\title{
Burden and Coping Mechanisms among Caregiver for Old Adult with advanced illness.
}

\author{
Nagwa Fawzy Sayed Ahmed (1), Mohamed Yasser Saif ${ }^{(2,3)}$, Sameer Hamedy ${ }^{(1)}$
}

(1) Department of Community Health Nursing Faculty of Nursing, Beni-Suef University, Beni Suef, Egypt

(2) Department of Ophthalmology, Faculty of Medicine, Beni-Suef University, Beni Suef, Egypt

(3) National Institute for Longevity Elderly Sciences (NILES), Beni-Suef University, Beni Suef, Egypt

Email: nagwa.nana2014@Gmail.com

\begin{abstract}
There were 727 million persons aged 65 years or over in the world in 2020 . Over the next three decades, the global number of older persons is projected to more than double, reaching over 1.5 billion in 2050 The aim of this study was to assess burden and coping mechanism among care giver for old age with advanced illness. A descriptive design is utilized in this study. A Convenience sample of caregivers was used it composed of 100 of caregivers and their patients who match the criteria: primary caregivers who provide care for the patients for at least one year and accept to participate in the study. Two tools were utilized 1: Interviewing questionnaire composed of 3 parts, Socio-demographic data, medical history of the patients, coping strategies used by the care giver to reduce 2 to assess burden of caregivers. The result the current study revealed (43\%) of the studied caregivers reported high level of burden and stress, flowed (32\%) reported medium level of burden and $(25 \%)$ reported low level of burden. This study conducted that caregiver factors as Age, gender, educational level, income status, knowledge of the diseases, and coping., patient factors (Age, clinical symptom, and disability in daily life), and environment factors (Health services and its utilization, and social support.) are major factors that affected caregivers' burden. The present study recommended that Provide guideline as well as clinical training to assist caregivers of chronic disease patients at home This helps them deal with the burden of care and manage the stress associated with it.
\end{abstract}

Key words: burden, coping mechanisms, caregiver, old adults, advanced illness.

\section{$\underline{\text { Received : 4/5/2021 }}$ Accepted : 20/5/2021 $\quad$ Published : 1/6/2021}

\section{Introduction}

Aging is a natural process that begins in the prenatal stage of life and lasts until death. It is caused by irreversible cells and systems degeneration. Age is not a pathological process, but is composed of physiological, psychological, chronological, and sociological changes. ${ }^{(1)}$ Physiological age is used to express loss of structure and function. It also used to indicate decreased awareness, learning and problem-solving skills; And sociological age to express the decline and loss of the value given to people by society. Age refers to the process of gradual change by which the properties of materials, structures or systems change (for the better or for the worse)., due to biological, chemical, or physical agents over time or with use Corrosion, obsolescence, and weathering are some of the effects of aging. (2) 
According to WHO, old age means that people's ability to meet environmental requirements beyond their control is reduced, and people sixty-five years and older are identified in chronological order. According to the World Health Organization, the classification by age is as follows: Young old ages are defined as 65-75 years old, and they represent a transition period from working life to retirement. Advanced old age is defined as being between the ages of 75 and 85 , and it is during this time that functional losses begin to be observed. 85 years and older are considered very advanced old ages, requiring special care and support. ${ }^{(3)}$

The aging process is natural, and people must go through many changes in their lives. It is estimated that by 2050 , the elderly population will double again, reaching nearly 2.1 billion by then. It is estimated that by 2030, there will be more elderly people than children. Children under the age of 10 (1.41 billion vs. 1.35 billion); Projections show that by 2050 , there will be more older people aged 60 and up than teenagers and young people aged 10 to 24. (2.1 billion versus 2.0 billion). Globally, the number of people aged 80 and up is expected to more than triple between 2017 and 2050, increasing from 137 million to 425 million. ${ }^{(4)}$

Two-thirds of the world's elderly live in developing countries, where their numbers are increasing higher than in developed countries. By 2050, it is projected that approximately 8 out of 10 of the world's elderly will be living in developed countries. ${ }^{(5)}$

Egypt, as a developing country, is also dealing with the emerging problem of an increasing number of elderly people. The proportion of people aged 60 and up was 4.4 percent in 1976, 5.75 percent in 1996, and 6.27 percent in 2006. The ratio is forecast to be 6.9 percent in 2015, 9.2 percent in 2021, and 20.8 percent in 2050 . This suggests that by that time, approximately 20 million Egyptians would be classified as elderly; a large number that resembles a complete nation in certain parts of the world. ${ }^{(6)(7)}$

The predicted rise in older adults around the world, and in Egypt in particular, is associated with chronic diseases. Chronic diseases are chronic conditions that necessitate constant care, periodic supervision, assistance, and maintenance in order to improve an individual's functionality. Chronic diseases are on the rise and have been identified as the leading cause of death worldwide. Chronic diseases will not only change certain aspects of patients' lives, but also bring different burdens and responsibilities those who provide caregiving at home or in a hospital setting. ${ }^{(8)}$

Caregiving is the method of carrying out the tasks and duties of caregiving and is not limited to a particular form of assistance; rather, it includes phycological, emotional, physical, and financial support. Routine health care issues such as drug consumption, medications prescription, and follow-up, personal care such as washing, feeding, toileting, dressing, transportation, shopping, petty housework, money management, and, and other issues are all addressed. Parents are usually responsible for caring for the sick, which is regarded as a family responsibility It is not possible to choose or intend to become a caregiver, which places family members with great responsibilities. Some caregivers may 
find this to be rewarding helpful, while others find it difficult and stressful Caregivers' mental or physical wellbeing, social life, and financial status have all deteriorated as a result of caring for their families, according to the concept of caregiver burden. ${ }^{(\mathbf{9})(\mathbf{1 0})}$

Caregivers are known as the person or persons who are most closely involved in caring for the elderly patient and assisting the patient to accommodate and maintain his chronic illness during treatment Family caregivers are people who meet the majority of the patient's physical, psychological, emotional, social and financial, care needs across the continuum of care, from hospitalization to home care, without being compensated. Caregivers are people who deal with stigmatic convictions on a regular basis and are usually a close relative, parent, or spouse. (11)

Since the extended family system has been practiced for several years in Egypt, elderly people are mostly assisted by their relatives. Everyone's life revolves around their family. Thus, elderly care has traditionally been the responsibility of family members, but in today's multicultural society, caregivers bear the burden of caring for elderly people at home. Reduced family size, two-career families, and improved life expectancy are the key reasons for this. Family support is influenced by geographic mobility, limited economic ability, and a shift in attitude toward family obligations. Meanwhile, as people age, their physical and cognitive abilities deteriorate. ${ }^{(6)(12)}$

Caregiver's burden is defined as the caregiver's perception of their physical and mental state, including their emotions, psychological state, personal importance and social life, which may be the result of caring for their family. The accumulation of activities can generate stress and affect many aspects of a person's life, putting the quality of life of the caregiver at risk. The burden of caregivers is defined as objective and subjective negative consequences, such as psychological stress, physical health problems, social and financial problems, family relationships breakdown. Desperate relationships and feelings caused by caregiver pressure. ${ }^{(13)(14)(15)}$

Caring for elderly patients may influence both objective and subjective aspects of caregivers' lives, including physical, psychosocial, and emotional health, morale, work, economics, social activity, relationships, and sexual life. Studies that assess the psychological impact of caring have found that the level of anxiety and depression of caregivers is higher than that of the general population. Caregivers who provide informal care, from physical assistance to psychological. Therefore, these caregivers may encounter high levels of burden as a result of the patients' and caregivers' characteristics. This burden may have a negative impact on the caregivers' health, social life, and overall well-being. As a result, burden in all phases, including physical burden, psychosocial burden, emotional burden, and economic burden, has a negative impact on the lives of both caregivers and their families. ${ }^{(16)}$

Caregivers usually do not encounter difficulties until signs of burnout appear. Financial support for the elderly cannot be covered either. In addition, the lack of publicly funded elderly care infrastructure may make it difficult to care for the elderly. In developed 
countries, the governments play important roles in helping the elderly, while in developing countries, families are the primary caregivers for the elderly, the majority of elderly people rely entirely on family members for support. ${ }^{(17)}$

Caregiver burden is correlated with several interconnected factors, including sociodemographic variables for both patients and caregivers. Caregivers' health status, time spent caring, and job complexity, subjective awareness and coping are all predictors of family caregiver stress., as well as environmental factors such as health facilities and their use, as well as social support. ${ }^{(18)}$

Coping strategies are individuals' cognitive and behavioral efforts to interpret and solve challenges, which typically includes all analytical studies that define Coping as the mechanism by which a person attempts to handle stress. The emotion-focused coping mechanism includes the ability to forget about the issue or to seek emotional help from others. Acceptance (accepting the truth of what happened and learning to deal with it); emotional support (getting emotional support, comfort, and empathy from others); humor (joking about it, making fun of the situation); and constructive reframing (trying to see it in a different light, making it sound more positive, and looking for something positive). religion (trying to find solace in my religious or spiritual beliefs and prayer meditation. ${ }^{(19)}$

Individuals who use the problem-focused coping strategy tend to deny and objectively evaluate the problem in order to catch the likelihood of modifying or dominating it in order to minimize the negative effects of mental stress. Problem-solving abilities aid in determining the root of a problem and devising an appropriate solution. Active coping (concentrating my attention on doing something about the situation I'm in/taking steps to try to make things better); instrumental support (get help and advice from others)0; and planning (trying to come up with a solution on what to do/ think carefully about the steps to follow) were the problem-focused tactics most commonly used. ${ }^{(20)}$

Dysfunctional coping mechanisms mediate the relationship between problem habits and depressive symptoms to some extent. The following coping mechanisms were the most widely used: behavioral isolation (giving up trying /the effort to cope); denial and rejection (telling yourself that this is not true /refusing to accept that it has happened). Selfdistraction (turning to work or other tasks to keep my mind off things/doing something to make me think about it less); self-blame (criticizing/accusing myself for things that happened); substance use (using alcohol or other substances to make me feel better/to help me get through it); venting (saying things to get rid of unpleasant emotions /express my negative emotions). ${ }^{(21)}$

Nurses can help caregivers reduce uncertainty and improve coping by explaining the factors that lead to caregiver burden and uncertainty and assisting caregivers in anticipating the effects of the caregiving position. Nurses educate family members so that they can accept and provide treatment safely. determining training requirements, disseminating knowledge and involve family members. In discharge plans and patient- 
related decisions will increase self-esteem and be willing to accept help from family members. ${ }^{(22)}$

Nurses offer understandable information to family caregivers in a variety of ways, and they do not expect family caregivers to seek information on their own. Along with family members, nurses play an important role in addressing family needs and delivering home care. Nurses provide the necessary services to family members as well as provide them with the necessary guidance. Nurses assist family members with home care tasks. Nurses are aware about counselors such as psychologists and other supportive organizations and may refer caregivers to them if necessary. ${ }^{(23)}$

\section{Significance of the study}

Caregiving influences all aspects of life, including the physical, psychosocial, financial, and spiritual aspects. The most common physical problems identified by caregivers included difficulty falling asleep, exhaustion and fatigue, discomfort, lack of physical strength, loss of appetite and the loss of weight. Caregivers interrupt social connections, events, and activities because their attention and time are concentrated on the patient and their rehabilitation. Caregivers place a financial burden on family members, both in in terms of direct expenses and recent income and benefits. Long-term financial consequences of caregivers include a lack of retirement savings. (24)

The emotional component of the caregiver's experience can be characterized as intensely emotional, full of hope and fear for the caregiver's desperate situation. Caregivers are more likely to develop unhealthy habits such as smoking, becoming sedentary, and overeating. The caregiver suffers from insomnia. the immune system Weakness, increased susceptibility to colds and infectious diseases. ${ }^{(25)}$

Determining the relationships between stress and the social, physical, emotional, and economical aspects burdens of caregivers with chronic and advanced diseases will help protect and promote successful coping strategies to help caregivers manage their stress and the health of patients. Caregivers attempted to deal with the challenges they faced, using both effective and unsuccessful coping strategies. caregivers should be aware of the connection between caregiving and stress, as well as coping strategies. Caregivers should try to shift people's attitudes toward positive coping mechanisms in this direction. (26)

\section{Aim of the study.}

To assess burden and coping mechanism among care giver for old age with advanced illness.

\section{Subjects and Methods}

\section{Research design:}

A descriptive design was utilized to assess to assess burden and coping mechanism among care giver for old age with advanced illness. 


\section{Research Setting:}

The current study will be conducted in Beni-Suef university hospital.

\section{Study subject}

Subjects in this study were all the caregivers who match the criteria of the study include 100 elderly patients and 100 caregivers from estimated total 2500 elderly patient and their caregivers visiting Beni suef university hospital.

A Convenience sample of caregivers was selected according to the following criteria: primary caregivers who provide care for the patients for at least one year and accept to participate in the study.

\section{Data collection tools:}

\section{Tool of the study:}

\section{Tools of data collection}

Tools were used by the researcher for the collection of the required data based on review of relevant literature.

1: Interviewing questionnaire was developed by the researcher, and it composed of 3 parts: -

\section{Part I: Socio-demographic data (appendix I):}

it consists of 10 questions, and was designed to collect data about age, educational level, marital status, family members, monthly income, practicing exercise, working hours, sleeping hours, experience/ year, and department.

\section{Part II: medical history of the patients}

Part III: Coping strategies used by the care giver to reduce burden.

\section{PART VI: to assess burden of caregivers.}

\section{Tools Validity:}

Face and content validity of the study tools was assessed by jury group consisted of five experts (They are Faculty members of Community Health Nursing Department at Beni-Suef University). Jury group members judge tools for comprehensiveness, accuracy, and clarity in language. Based on their recommendation, correction, addition and / or omission of some items was done.

\section{Field work:}

Data collection of the study was started at the beginning of March 2019 and completed by the end of June 2019. The researcher attended at the geriatric units three days per week from 9am to 2pm at Beni-Suef university hospital for all the older adult is already 
diagnosed with multi comorbidities disease', receiving medical and nursing care for at least 3 months. The researcher first explained the aim of the study to the participants and reassures them that information collected will be treated confidentiality and that it will be used only for the purpose of the research.

\section{III- Administrative Design}

An official letter requesting permission to conduct the study was directed from the dean of the faculty of nursing Beni - Sueif University to director at Beni-Suef university hospital to obtain their approval to carry out this study. This letter included the aim the study and photocopy from data collection tools to get their permission and help for collection of data.

\section{Ethical Consideration}

The study was conducted with careful attention to ethical standards of research and rights of participants. Verbal consent was taken from each nurse as well as patient to participate in this study. During the initial interview, the purpose of the study and the procedures were explained to the participants. The subjects were assured that all information will be confidential and will be used for the research only to assure the confidentiality of the participants. Participants will be assured that their participation in the study is voluntary and that they can refuse to participate in the study. It will be explained that there are no costs to participate in the study.

\section{IV-Statistical Design:}

The collected data were organized, tabulated, and statistically analyzed using SPSS version 19 (Statistical Package for Social Studies) created by IBM, Illinois, Chicago, USA. For numerical values, the mean and standard deviations were calculated. Chi square test was used to detect the statistical differences between variables. When chi square test was not suitable due to presence of observations with small number, Monte Carlo exact test was used. data. The correlation between study variables was calculated using Pearson's correlation coefficient the level of significant was adopted at $p<0.05$.

\section{Results:}

Table (1) shows the distribution of socio-demographic characteristics of studied caregiver, the table shows that. (67\%) of the study sample were female and $(33 \%)$ were male. In the term of caregivers age, it was observed that half of the study sample $(50 \%)$ were at the age between (30) and (40) and (29\%) were at the age between (41) and (50) while the rest (21\%) were at the age less than (30). In concern of education, all the study sample $(100 \%)$ had received formal education. around half of the participants $(45 \%)$ had received secondary education and (33\%) studied in primary school. There were $(22 \%)$ had received higher education. As to social status, less than two- thirds of participants (64\%) were married and more than one - third (34\%) were single. Referring to economic status, it was shown that more than three- fifths $(62 \%)$ of the study sample had economic problems 
while less than two -fifths (38\%) had no economic problems. In terms of occupation, more than three- fifths $(61 \%)$ of the study sample were employed and had work whereas nearly two- fifths (39\%) were unemployed. As to residences less than two thirds the participants $(63 \%)$ lived in rural areas such as and less than two - fifths (37\%) lived in urban areas such as cities and towns.

Table (1) Distribution of studied care giver according to their sociodemographic characteristics

\begin{tabular}{|l|l|l|}
\hline items & N & $\%$ \\
\hline Gender & & \\
\hline Male & 33 & 33 \\
\hline Female & 67 & 67 \\
\hline Age & & \\
\hline Less than 30 & 21 & 21 \\
\hline $30-40$ & 50 & 50 \\
\hline $41-50$ years & 29 & 29 \\
\hline Education & & \\
\hline Primary & 33 & 33 \\
\hline Secondary & 45 & 45 \\
\hline High education & 22 & 22 \\
\hline Social status & & \\
\hline Married & 66 & 66 \\
\hline Single & 34 & 34 \\
\hline Economic status & & \\
\hline Problematic & 62 & 62 \\
\hline Non problematic & 38 & 38 \\
\hline occupation & & \\
\hline Employed & 61 & 61 \\
\hline Unemployed & 39 & 39 \\
\hline Residence & & \\
\hline Rural & 63 & 63 \\
\hline Urban & 37 & 37 \\
\hline
\end{tabular}

Table (2): describes the distribution of studied old age patients according to their history of the disease. The table reveals that. that more than three - quarters $(78 \%)$ of patients with hypertension. and more than half $(56 \%)$ had medical history of congestive heart failure. More than one - fifth $(23 \%)$ of patients had Renal failure. More than twothird of patients $(67 \%)$ had diabetes mellitus. while more than three - fifths $(61 \%)$ of patients had liver disease. 
Table (2) Distribution of studied old age patients according to their history of the disease.

\begin{tabular}{|l|c|c|}
\hline Items & $\mathrm{N}$ & $\%$ \\
\hline Medical history & & \\
\hline Congestive heart failure & 56 & 56 \\
\hline DM & 67 & 67 \\
\hline HYPERTENSION & 78 & 78 \\
\hline RENAL FAILURE & 23 & 23 \\
\hline LIVER DISEASES & 61 & 61 \\
\hline
\end{tabular}

Table (3): reveals that more than four - fifths (82\%) of patients were dependent on toileting while less than one - fifth (18\%) were independent. more than four - fifths $(83 \%)$ the study sample were dependent in feeding while less than one - fifth (17\%) were independent. the dressing and continence appeared in close proportions $(65 \%)$ and $(63 \%)$ respectively for two- thirds of the study sample while more than one- third (35\%) was independent in dressing and less than two - fifths (37\%) were independent in continence. Nearly three quarters of the sample (73\%) were dependent in transferring the rest were not.

Table (3) Distribution of studied old age patients according to their level of independence.

\begin{tabular}{|l|c|c|c|c|}
\hline \multirow{2}{*}{ Items } & \multicolumn{2}{|c|}{ dependence } & \multicolumn{2}{c|}{ independence } \\
\cline { 2 - 5 } & $\mathrm{N}$ & $\%$ & $\mathrm{~N}$ & $\%$ \\
\hline Bathing & 71 & 71 & 29 & 29 \\
\hline Dressing & 65 & 65 & 35 & 35 \\
\hline Toileting & 82 & 82 & 18 & 18 \\
\hline Transferring & 73 & 73 & 27 & 27 \\
\hline Continence & 63 & 63 & 37 & 37 \\
\hline Feeding & 83 & 83 & 17 & 17 \\
\hline
\end{tabular}

Figure (1): shows that around three- fifths (59\%) of studied sample were unsatisfied about their level of knowledge whereas two - fifths (41\%). were satisfied 


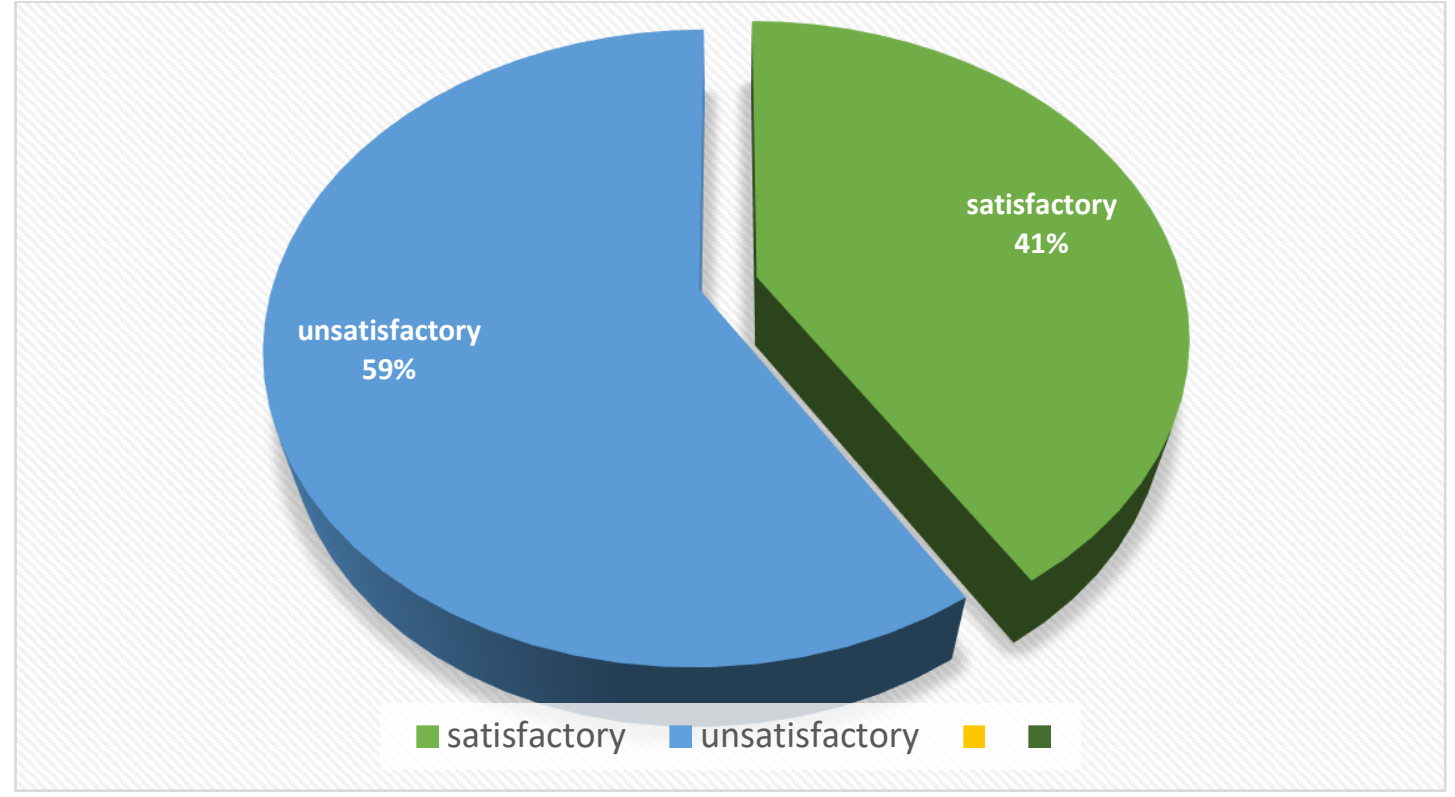

Figure (1) Distribution of studied sample according to their total level of knowledge

Table (4): The data reveals that half of the study sample (50\%) rarely stressed as they felt embarrassed over their relative's behaviors. There was one - quarter (25\%) rarely stressed that their relatives ask for more help than they need also one - quarter (25\%) rarely stressed as they were uncertain about what to do about their relatives. Data also reveals that three - fifths $(60 \%)$ of the study sample sometimes stressed that they did not have time for themselves because of the time they spent with their relatives. There were more than half $(55 \%)$ of the study sample sometimes stressed as they did not have as much privacy as they would like because of their relatives also There were more than half (55\%) of participants sometimes stressed that their relatives seem to expect to take care of them as if they were the only persons the relatives could depend on. It is also shown that three - fifths $(60 \%)$ of participants usually felt stress about the future of their relatives. there were more than half $(51 \%)$ of the study sample usually stressed that their relative need more care from them.

Figure (2): reveals that more than two - fifths (43\%) of the study sample had high level of stress. There was around one- third (32\%) of participants experienced medium level of stress whereas one- quarter $(25 \%)$ of the o participants experienced low level of stress. 
Table (4) Distribution of studied sample according to their stress level

\begin{tabular}{|c|c|c|c|c|c|c|}
\hline \multirow{2}{*}{ Question } & \multicolumn{2}{|c|}{ Rarely } & \multicolumn{2}{|c|}{ Sometimes } & \multicolumn{2}{|c|}{ Usually, } \\
\hline & $\mathrm{N}$ & $\%$ & $\mathrm{~N}$ & $\%$ & $\mathrm{~N}$ & $\%$ \\
\hline $\begin{array}{l}\text { 1- Do you feel that your relative asks for } \\
\text { more help than he/she needs? }\end{array}$ & 25 & 25 & 40 & 40 & 35 & 35 \\
\hline $\begin{array}{l}\text { 2- } \begin{array}{l}\text { Do you feel that because of the time you } \\
\text { spend with your relative that you don't } \\
\text { have enough time for yourself? }\end{array} \\
\end{array}$ & 15 & 15 & 60 & 60 & 25 & 25 \\
\hline $\begin{array}{l}\text { 3- Do you feel stressed between caring for } \\
\text { your relative and trying to meet other } \\
\text { responsibilities for your family or work? }\end{array}$ & 19 & 19 & 46 & 46 & 35 & 35 \\
\hline $\begin{array}{l}\text { 4- Do you feel embarrassed over your } \\
\text { relative's behaviour? }\end{array}$ & 50 & 50 & 24 & 24 & 26 & 26 \\
\hline $\begin{array}{l}\text { 5- Are you afraid what the future holds for } \\
\text { your relative? }\end{array}$ & 10 & 10 & 30 & 30 & 60 & 60 \\
\hline $\begin{array}{l}\text { 6- Do you feel your relative is dependent on } \\
\text { you? }\end{array}$ & 23 & 23 & 45 & 45 & 32 & 32 \\
\hline $\begin{array}{l}\text { 7- Do you feel your health has suffered } \\
\text { because of your involvement with your } \\
\text { relative? }\end{array}$ & 27 & 27 & 43 & 43 & 30 & 30 \\
\hline $\begin{array}{l}\text { 8- Do you feel that you don't have as much } \\
\text { privacy as you would like because of } \\
\text { your relative? }\end{array}$ & 12 & 12 & 55 & 55 & 33 & 33 \\
\hline $\begin{array}{l}\text { 9- } \begin{array}{l}\text { Do you feel that your social life has } \\
\text { suffered because you are caring for your } \\
\text { relative? }\end{array} \\
\end{array}$ & 15 & 15 & 40 & 40 & 45 & 45 \\
\hline $\begin{array}{l}\text { 10- Do you feel uncomfortable about having } \\
\text { friends over because of your relative? }\end{array}$ & 18 & 18 & 42 & 42 & 40 & 40 \\
\hline $\begin{array}{l}\text { 11- Do you feel that your relative seems to } \\
\text { expect you to take care of him/her as if } \\
\text { you were the only one he/she could } \\
\text { depend on? }\end{array}$ & 16 & 16 & 55 & 55 & 29 & 29 \\
\hline $\begin{array}{l}\text { 12- Do you feel that you don't have enough } \\
\text { money to take care of your relative in } \\
\text { addition to the rest of your expenses? }\end{array}$ & 11 & 11 & 48 & 48 & 41 & 41 \\
\hline $\begin{array}{l}\text { 13- Do you feel that you will be unable to } \\
\text { take care of your relative much longer? }\end{array}$ & 19 & 19 & 50 & 50 & 31 & 31 \\
\hline $\begin{array}{l}\text { 14- Do you feel uncertain about what to do } \\
\text { about your relative? }\end{array}$ & 25 & 25 & 40 & 40 & 35 & 35 \\
\hline $\begin{array}{l}\text { 15- Do you feel your relative need more care } \\
\text { from you? }\end{array}$ & 23 & 23 & 26 & 26 & 51 & 51 \\
\hline
\end{tabular}






- low level of sress medium level of stress $\quad$ high level of stress

Figure (2) Distribution of studied sample according to their total level of stress

Table 5) the data reveled that near half (45\%) of the study sample do not use exercise. Also, near half $(45 \%)$ of the study sample sometimes use behavioral disengagement to cope with stress. There were around two- thirds (65\%) of the study sample do not use acceptance to cope with stress also (65\%) of the study sample usually use Instrumental Support to cope with stress and four - fifths $(80 \%)$ of the study sample usually use religion to cope with stress. data also revealed that one -tenth $(10 \%)$ of the study sample do not use self-blame also three - quarters $(75 \%)$ do not use Prescribed Medications to cope with stress. there were less than two- thirds (64\%) do not use substance and $(60 \%)$ do not use denial to cope with stress. Whereas less than one - fifth (18\%) of the participants usually use denial.it is shown that more than two - fifth (44\%) use positive reframing whereas more than one - fifth $(21 \%)$ do not use.

Table (5) Distribution of studied sample according to their coping.

\begin{tabular}{|l|c|c|c|c|c|c|}
\hline \multirow{2}{*}{ Question } & \multicolumn{2}{|c|}{ Usually, } & \multicolumn{2}{c|}{ Sometimes } & \multicolumn{2}{c|}{ Do not use } \\
\cline { 2 - 7 } & $\mathrm{N}$ & $\%$ & $\mathrm{~N}$ & $\%$ & $\mathrm{~N}$ & $\%$ \\
\hline 1- Exercise & 27 & 27 & 28 & 28 & 45 & 45 \\
\hline 2- Behavioral Disengagement & 19 & 19 & 45 & 45 & 34 & 34 \\
\hline 3- Acceptance & 14 & 14 & 21 & 21 & 65 & 65 \\
\hline 4- Planning & 22 & 22 & 28 & 28 & 50 & 50 \\
\hline 5- Instrumental Support & 65 & 65 & 21 & 21 & 14 & 14 \\
\hline 6- Emotional Support & 37 & 37 & 18 & 18 & 45 & 45 \\
\hline 7- Active Coping & 27 & 27 & 30 & 30 & 43 & 43 \\
\hline 8- Religion & 80 & 80 & 10 & 10 & 10 & 10 \\
\hline 9- Self-blame & 55 & 55 & 35 & 35 & 10 & 10 \\
\hline 10- Prescribed Medications & 12 & 12 & 13 & 13 & 75 & 75 \\
\hline 11- Self-distraction & 20 & 20 & 25 & 25 & 45 & 45 \\
\hline 12- Positive Reframing & 44 & 44 & 35 & 35 & 21 & 21 \\
\hline 13- Substance Use & 17 & 17 & 19 & 19 & 64 & 64 \\
\hline 14- Humor & 30 & 30 & 25 & 25 & 45 & 45 \\
\hline 15- Denial & 18 & 18 & 22 & 22 & 60 & 60 \\
\hline 16- Venting & 45 & 45 & 34 & 34 & 21 & 21 \\
\hline
\end{tabular}


Table (6): shows that There approaching statistically significant relation between care giver level of knowledge and their residence with $(p=.7)$. There is a highly statistically significant relation between care giver level of knowledge and their sex $(p=.001)$ There is a very highly statistically significant relation between care giver level of knowledge and their education ( $p=.0004)$. there is a highly significant relation between care giver level of knowledge and their age were $(p=.004)$. the results found that the three variables such as age, gender and education had positive correlation with level of knowledge with $(p<.05)$.

Table (6) Association between socio-demographic data of studied sample and their total level of knowledge

\begin{tabular}{|c|c|c|c|c|c|c|c|}
\hline \multirow[t]{2}{*}{ Items } & \multirow{2}{*}{$\mathrm{N}$} & \multicolumn{2}{|c|}{ Satisfactory } & \multicolumn{2}{|c|}{ Unsatisfactory } & \multirow{2}{*}{$\mathrm{X}^{2}$} & \multirow{2}{*}{$\mathrm{P}$} \\
\hline & & $\mathrm{N}$ & $\%$ & $\mathrm{~N}$ & $\%$ & & \\
\hline \multicolumn{8}{|l|}{ Gender } \\
\hline Male & 33 & 21 & 63.6 & 12 & 36.3 & \multirow{2}{*}{10.4} & \multirow{2}{*}{.001} \\
\hline Female & 67 & 20 & 29.8 & 47 & 70.2 & & \\
\hline \multicolumn{8}{|l|}{ Age } \\
\hline Less than 30 & 21 & 15 & 71.4 & 6 & 28.6 & \multirow{3}{*}{10.7} & \multirow{3}{*}{.004} \\
\hline $30-40$ & 50 & 18 & 36 & 32 & 64 & & \\
\hline $41-50$ years & 29 & 8 & 27.5 & 21 & 72.5 & & \\
\hline \multicolumn{8}{|l|}{ Education } \\
\hline Primary & 33 & 9 & 27.2 & 24 & 72.5 & \multirow{3}{*}{15.6} & \multirow{3}{*}{.0004} \\
\hline Secondary & 45 & 15 & 33.3 & 30 & 66.7 & & \\
\hline High education & 22 & 17 & 77.2 & 5 & 22.8 & & \\
\hline \multicolumn{8}{|l|}{ Residence } \\
\hline Rural & 63 & 25 & 39.6 & 38 & 60.4 & \multirow[b]{2}{*}{.12} & \multirow[b]{2}{*}{.7} \\
\hline Urban & 37 & 16 & 43.2 & 21 & 56.8 & & \\
\hline
\end{tabular}

Table (7): shows that there is nonsignificant relation between care giver level of stress and their sex $(p=.11)$. there is a very highly statistically significant relation between studied sample and their education level $(p=.0001)$. there is approaching significant relation between care giver level of stress age $(p=.7)$. There is a highly statistically significant relation between care giver level of stress and their residence $(p=.001)$. the results found that two variables such as education and residence had significant correlation with level of stress with $(p<.05)$. 
Table (7) Association between socio-demographic data of studied sample and their total level of stress 11829

\begin{tabular}{|c|c|c|c|c|c|c|c|c|c|}
\hline \multirow[t]{2}{*}{ Items } & \multirow[t]{2}{*}{$\mathrm{N}$} & \multicolumn{2}{|c|}{ LOW } & \multicolumn{2}{|c|}{ Medium } & \multicolumn{2}{|c|}{ High } & \multirow[t]{2}{*}{$\mathrm{X} 2$} & \multirow[t]{2}{*}{$\mathrm{p}$} \\
\hline & & $\mathrm{N}$ & $\%$ & $\mathrm{~N}$ & $\%$ & $\mathrm{~N}$ & $\%$ & & \\
\hline \multicolumn{10}{|l|}{ Gender } \\
\hline Male & 33 & 4 & 12.1 & 12 & 36.36 & 17 & 51.5 & \multirow[t]{2}{*}{4.3} & \multirow[t]{2}{*}{.11} \\
\hline Female & 67 & 21 & 31.3 & 20 & 29.85 & 26 & 38.8 & & \\
\hline \multicolumn{10}{|l|}{ Age } \\
\hline Less than 30 & 21 & 7 & 33.3 & 6 & 28.57 & 8 & $\begin{array}{l}38.09 \\
5\end{array}$ & \multirow[t]{3}{*}{1.8} & \multirow[t]{3}{*}{0.7} \\
\hline $30-40$ & 50 & 10 & 20 & 18 & 36 & 22 & 44 & & \\
\hline $41-50$ years & 29 & 8 & 27.58 & 8 & 27.58 & 13 & 44.82 & & \\
\hline \multicolumn{10}{|l|}{ Education } \\
\hline Primary & 33 & 3 & 9.09 & 16 & 48.48 & 14 & 42.42 & \multirow[t]{3}{*}{28.3} & \multirow{3}{*}{$\begin{array}{l}0.000 \\
1\end{array}$} \\
\hline Secondary & 45 & 8 & 17.7 & 11 & 24.4 & 26 & 57.7 & & \\
\hline $\begin{array}{l}\text { High } \\
\text { education }\end{array}$ & 22 & 14 & 63.63 & 5 & 22.72 & 3 & 13.63 & & \\
\hline \multicolumn{10}{|l|}{ Residence } \\
\hline Rural & 63 & 10 & 15.87 & 18 & 28.57 & 35 & 55.55 & \multirow[t]{2}{*}{12.5} & \multirow[t]{2}{*}{.001} \\
\hline Urban & 37 & 15 & 40.54 & 14 & 37.83 & 8 & 21.62 & & \\
\hline
\end{tabular}

\section{DISCUSSION}

Caregivers care for individuals who need some level of ongoing assistance with daily activities on a regular or daily basis. Care recipients may reside in a residential or institutional setting and suffer from chronic illnesses or debilitating conditions. Some caregiving aspects can be rewarding; however, caregivers may be at a higher risk of negative health consequences. This can be stress, depression, trouble maintaining a balanced lifestyle, and so on. As the world's population of elderly people grows, so s does the number of caregivers. ${ }^{(27)}$ In 2020, there will be 727 million people in the world who are 65 or older. Over the next three decades, the global population of the elderly is expected to more than double, reaching over 1.5 billion by 2050. The proportion of the global population aged 65 and up is projected to rise from 9.3 percent in 2020 to 16.0 percent by 2050. ${ }^{(5)}$

Therefore, the current study aims to assess the burden and coping mechanism among caregivers for old age with advanced illness. The study sample size was 100 elderly patients and 100 caregivers from an estimated total of 2500 elderly patients and their 
caregivers visiting Beni suief university hospital it was a convenience sample of caregivers according to the following criteria. Accept to participate, provide care for the patient for at least one-year, Primary caregiver, exclusion criteria, and paid caregivers and elderly patients residing in nursing homes.

Referring to caregivers' Gender the results of the current study revealed that one third of the caregiver was male and two -thirds were female this proves that there were more women than men as caregivers This finding can be explained by the fact that women are frequently required to play the traditional role of caregiving, women's various caring roles, and other gender-related difficulties, such as spending more time with older adult patients than male caregivers. Furthermore, getting less help with caregiving activities and financial support. This finding was consistent with the findings of (28) in their study conducted in Bangladesh, which revealed that three-quarters of caregivers were female, and one-quarter were male. Also, this finding is consistent with the study by (29) in Zimbabwe, ${ }^{(30)}$ in Egypt, and ${ }^{(31)}$ in the United States of America who reported that more than two-thirds in their study sample were female and one-third of the caregivers were male. These findings revealed that women's positions as caregivers are profoundly ingrained in cultural gender roles and conventional family concepts. According to the findings, the majority of caregivers are women, which is in line with our culture, in which housewives typically take on the role of caregiver while male family members are responsible for getting money outside the home to support their families. A recent national survey in 2020 suggested that approximately two in every three caregivers are women ${ }^{(32)}$. In the same vein, ${ }^{(33)}$ asserted that female caregivers bear greater responsibilities than male caregivers and clarified that they are elderly people's wives or adult daughters in their middle age. They're much more likely to work outside the house. On the other hand, the study of ${ }^{(34)}$ conducted in Iraq mentioned that about three-fifths of the caregivers in their study sample were male whereas nearly two-fifths of the caregivers were female.

In terms of age, the current study found that one-fifth of the caregivers were under thirty years old, half of the caregivers were between thirty and forty years old, and less than one-third of the caregivers were between forty and fifty years old. The majority of the studied family caregivers in the current study were in middle age. These results were supported by the study of ${ }^{(35)}$ conducted in Egypt who reported that the majority of their study sample aged less than fifty years old, $45.90 \pm 14.05$ years.

Regarding the social status of the caregivers, the result of the current study demonstrated that two-thirds of the study sample were married, and one-third were single. This was supported by the result of ${ }^{(36)}$ in his study conducted in Brazil who mentioned the same results that two-thirds of the study caregivers were married and one third were single. This is consistent with the findings of ${ }^{(37)}$ in his study conducted in Pakistan, who found that three-quarters of caregivers in their study sample were married and one-quarter were 
unmarried. On the other hand, the result of the study ${ }^{(38)}$ conducted in Saudi Arabia, revealed that nearly three-fifths were single, and more than two-fifths were married.

This finding revealed that the Egyptian family is known for being more welcoming and protective of its members due to a sense of responsibility to an unchangeable situation. Previous research in this regard, has suggested that accepting and understanding of the characteristics of the disease can help the family stay together, even when the patient's behavior is unpleasant during the illness. When the family caregivers accept the diagnosis and view a crisis positively, they can come up with creative solutions to their problems. (35)(39)

Concerning residence, the result of the present study illustrated that nearly twothirds of the caregivers lived in rural areas and more than one-third lived in urban areas This might be secondary to the agricultural nature of the sample setting (Beni Suef governorate). this result was in the line with ${ }^{(40)}$ in his study conducted in India who revealed that more than half of the caregivers belonged to the rural community, others nearly half of the caregivers being from an urban background.

On the other hand, a study conducted in Zimbabwe by ${ }^{(29)}$ found that approximately three-fifths of the caregivers in their study sample lived in townships, while the remaining two-fifths lived in low-density suburbs and rural areas. In addition, ${ }^{(41)}$ reported in their study conducted in Egypt that more than one-quarter of caregivers lived in rural areas whereas nearly three-quarters lived in urban areas.

Concerning the occupational status of caregivers, the current study found that nearly two-thirds of caregivers were employed, and more than one-third of caregivers were unemployed. This was consistent with the findings of a study conducted by ${ }^{(\mathbf{4 2})}$ in Jordan, who found that approximately two-thirds of caregivers were employed, and more than onethird were unemployed. It was also consistent with the findings of a study conducted in Nigeria ${ }^{(43)}$ reported that more than nine-tenths of their study sample was employed and less than one-fifth was unemployed.

However, in a study conducted by ${ }^{(\mathbf{4 4})}$ In Jordan, reported that more than four-fifths of caregivers were unemployed, while more than one-fifth of caregivers were employed. Furthermore, he supported these findings later in his study ${ }^{(45)}$ conducted in Jordan, in which he reported that less than two-thirds of caregivers were unemployed and more than one-third of caregivers were unemployed. In addition, the study conducted in Egypt by of (30) found that the majority of caregivers, approximately two-thirds, had no jobs, and more than one-tenth were employees .

Concerning the educational level, the current study found that all of the participants in the study sample obtained education at various stages, owing to the fact that education in Egypt is free for all and obligatory by law until the end of the middle school period. the 
high proportion of participants Nearly half of the caregivers had a secondary education, about one-third had a primary education, and more than one-fifth had a higher education. This was supported by a study conducted by ${ }^{(38)}$ in Saudi Arabia, which found that more than four-fifths of caregivers had a high school diploma or higher, and more than one-fifth had a bachelor's degree or higher. This contrasted to the study of ${ }^{(\mathbf{4 6})}$ conducted in Egypt. Who claimed that two-thirds of caregivers were illiterate, that only one-fifth had a secondary education, and that only one-tenth had a university education level.

In terms of the medical history of the old age patients, the current study illustrated that, more than three-quarters of patients in the study population had hypertension, more than half had a medical history of congestive heart failure, more than one-fifth of patients had renal failure, and two-thirds of patients had diabetes mellitus. While three-fifths of the patients had liver disease, this result may be clarified by the fact that chronic illnesses and co-morbidities become more common as people get older. These results contrasted with the findings of ${ }^{(47)}$ in their study conducted in Egypt, who found that more than two-fifths of the patients in their study sample had hypertension. And just about one-fifth had a history of congestive heart failure. Renal failure affected more than onetenth of the patients. Diabetes mellitus affected less than one-third of the patients. More than a tenth of the patients had liver failure.

Regarding old age patients according to their level of independence, the current study found that more than four-fifths of elderly patients were dependent on toileting, nearly three-quarters of patients were dependent on bathing, more than four-fifths of the study sample were dependent on feeding, nearly two-thirds of the patients were dependent on dressing, almost three-quarters of the sample were reliant on transferring, while more than three-fifths of patients were reliant on continence. The current study's results showed that the majority of the elderly were totally dependent on all everyday activities for more than two-thirds of their lives, while about one-third were completely independent. In the same vein, a slightly lower percentage was reported by ${ }^{(\mathbf{4 8})}$ in their study conducted in Egypt who revealed that more than half of the elderly were independent on toileting, more than half of the elderly were independent on bathing, nearly three- fifths of the elderly were independent on feeding, nearly three- fifths of the elderly were independent on clothing and the same percentage of elderly were dependent on mobilization. This means that more than half of the studied elderly were dependent on all activities of daily life.

Concerning the physical burden among family caregivers, nearly more than twofifths of the sample felt that their health had suffered because of involvement in inpatient care. these results were supported by the study of ${ }^{(49)}$ conducted in Vietnam who reported that nearly half of their participants felt that their health status was affected by the caregiving process. 
In terms of the psychological burden among family caregivers, the current study found that two-fifths of the study sample felt unsure about what to do about their relatives at times, and less than half felt overwhelmed between patient caring and trying to fulfill responsibilities for family or work, as well as feeling strained when around their patient. In addition, the sample sound to be irritated when their patients' needs or desires are not met, resulting in burden and tension. This is consistent with the study of ${ }^{\mathbf{( 5 0 )}}$ conducted in Brazil who claimed that the majority of caregivers suffered from Depression, anxiety, stress, overburdening, and substance use are particularly prevalent in the everyday lives of family caregivers of people with dementia, according to the studies reviewed.

In terms of the social burden of caregivers, the current study found that three-thirds of the study sample thought they had lost control of their lives as a result of the patients' disease, and two-fifths felt their social lives had been harmed. Additionally, more than twofifths felt that caring for the patient had harmed their relationships with other family members or friends.in a negative way. This is consistent with the findings of ${ }^{(51)}$ in Brazil, who found that more than three-fifths of their study sample felt quietly disconnected from their surroundings, social life, and social relations as a result of the caregiving process.

Regarding and financial burden, of the family caregiver, about nearly half sometimes feeling that they do not have enough money to take care of patient in addition to the rest of life. This in harmony with the study of ${ }^{(\mathbf{5 2})}$ in Egypt who stated that about two thirds sometimes feeling that they do not have sufficient money to take care of patient in addition to deal with daily expenses.

In terms of the level caregiver burden, the current study found that more than twofifths of the study sample experienced a high degree of burden. Almost one-third of the study participants reported a medium level of burden, while one-quarter reported low levels of stress. This may be due to a variety of factors, including the impact of caring for elderly patients on family members, health illiteracy, and a lack of coping mechanisms among caregivers that help them cope effectively with the stresses of advanced disease, as well as the impact of non-compliance with medication, prescription prices, a lack of community health services, and overlapping or conflicting roles in the family.

This is consistent with the findings of a study conducted by ${ }^{(\mathbf{5 3})}$ in the United States of America, which revealed that more than two- fifths of caregivers reported a high level of burden, more than one- third reported a medium level of burden, and more than onefifth reported a low level of caregiver burden. It was also endorsed by the study of (54) conducted in Nigeria who stated in his study that less than two- fifths of his study sample experienced severe burden, more than one-quarter of his study sample experienced moderate burden, and more than one-tenth of his study participants recorded a low level of burden. Also, it was supported by the study of ${ }^{(\mathbf{5 5})}$ conducted in Egypt who illustrated that more than two - fifths of their study sample reported a high and a moderate level of burden 
and more than one -fifth of the study participants reported a low level of burden. This result was in the line with the study of ${ }^{(\mathbf{5 6})}$ conducted in Nigeria who revealed that less than two -fifths of the study participants indicated a severe burden and one- third of the study participants experienced a moderate level of burden while participants indicated they experienced a mild burden. Also, it was in line with the study of ${ }^{(57)}$ conducted in Egypt who mentioned that two- thirds of her study sample reported sever burden and one third reported low burden.

On the other hand, the result of the current study was in contrast with the study of (58) conducted in Egypt who illustrated that the high level of burden was documented among more than two-thirds of the study family caregivers and less than one - third of the study sample reported a low level of burden. Furthermore, it contrasted with the findings of the study of (59) conducted in Egypt, who found that approximately less than one present of their study sample reported severe burden, more than two-fifths of caregivers reported moderate burden, less than two-fifths of participants experienced mild burden, and more than one-tenth of the study sample had no burden. The current finding was not in agreement with the study of ${ }^{(\mathbf{6 0})}$ conducted in Egypt who mentioned that less than one percent of their study sample reported severe burden and less than one - third of the study sample reported medium level of burden while less than half reported low level of burden and more than one - tenth experienced no burden. In addition, contrary to the study of ${ }^{(61)}$ conducted in Egypt, only one participant in the study sample revealed severe burden. More than onequarter of the study participants had a medium level of burden, three-fifths of the caregivers reported a low level of burden, and one-tenth of the participants had no burden Moreover, according to the findings of a study ${ }^{(62)}$ conducted in Brazil, more than two-thirds of the study sample indicated low burden, one-quarter of their study sample reported medium level burden, and less than one-tenth of the participants experienced severe level burden.

The current study's findings revealed that there is no significant relationship between caregivers' stress levels and their gender. The current study's findings revealed no gaps in the burden of caregiving between men and women. This was consistent with the study conducted in Iran by ${ }^{(20)}$ who claimed that there was no relationship between the gender of the caregiver and the level of branon.

In contrast, ${ }^{(63)}$ found a significant relationship between gender and burden in their study conducted in India. When compared to male caregivers, both females and wives perceived more burden as caregivers. Furthermore, in their study conducted in Egypt, (64) stated that no differences in gender and burden of care were identified. This finding was supported by a study conducted in Turkey by ${ }^{(65)}$ in which They demonstrated that a statistically significant relationship was found between caregiver burden and caregiver sex, which they explained by the fact that caregivers are mostly women according to their study. 
Also, ${ }^{(66)}$ stated in their study conducted in Brazil that the majority of Brazilian caregivers presented with high levels of burden, and women showed higher burden than men.

The current study's findings demonstrated that there is no significant relationship between caregiver level of stress and age, indicating that both younger and older caregivers faced the burden of caregiving. Every member of the family assisted in caregiving; women assisted in physical management, men organized medication and financial issues, and children assisted in environmental improvements, and even relatives and neighbors looked after patients This is inconsistent with the findings of a study conducted in Myanmar by ${ }^{(17)}$ which found that age has a significant relationship with burden, and the caregiving burden increases with age, with older caregivers experiencing higher levels of burden than younger caregivers.

The current study's findings revealed a highly significant association between caregivers' level of burden and their level of education. Caregivers with a high level of education had a low level of burden, which is consistent with a study conducted in Egypt by ${ }^{(67)}$ who claimed that there is a significant relationship between the level of education and the level of burden. on the contrast of that ${ }^{(\mathbf{6 4})}$ in their study conducted in Egypt reported that there was no significant relationship between the level of education and caregiver burden. In addition, a study conducted in India ${ }^{(63)}$ revealed that there is no relationship between education and burden.

The results of this study show that there is a highly significant correlation between the stress level of nursing staff and their place of residence. Caregivers in rural areas are more likely to experience higher burden than caregivers in cities, which may lead to more exposure. Due to the lack of advanced medical care in rural areas than in cities, they are forced to travel long distances to obtain medical care for their loved ones. This is consistent with the findings of a study conducted in China by ${ }^{(68)}$ ), which found a significant relationship between caregivers' place of residence and their level of burden. This contrasts with the findings of the study conducted in Egypt by ${ }^{(\mathbf{5 5})}$ who reported that there were no significant relationships between caregiver burden and caregiver residence, he added that the place where the caregivers lived was not correlated with the level of burden of the caregiver and the place where the caregivers lived of the caregivers was unrelated to the caregiver's level of burden.

The result of the present study found that two variables such as education and residence had a significant correlation with the level of stress $(p<.05)$. and the other two variables had a nonsignificant correlation with the level of stress.

Concerning caregivers' knowledge of their patients' diseases and emergencies, the current study found that approximately three-fifths of the studied sample were unsatisfied with their degree of knowledge, whereas two-fifths were satisfied. This was supported by 
a study conducted by ${ }^{\left({ }^{69}\right)}$ in Egypt, which found that nearly three-quarters of caregivers had inadequate knowledge about their patients' diseases, while one-quarter of caregivers were satisfied. In the same vein, a slightly higher percentage was indicated by the study of (70) conducted in Italy, which revealed that approximately three-quarters affirmed not knowing the disease, and with a lower percentage, approximately one-quarter aware of the diseases. This contradicts the findings of a study conducted in Saudi Arabia by ${ }^{(71)}$ which found that one-quarter of caregivers had a poor level of knowledge, three-fifths had a reasonable level of knowledge, and one-fifth had a strong level of knowledge.

the findings of this study demonstrated that, there is no significant relationship between caregiver level of knowledge and their residence place. There is no difference in knowledge levels between caregivers who live in rural areas and those who live in towns and cities because caregivers can obtain knowledge and information about their patients' diseases regardless of where they live. This is consistent with the findings of the study conducted in Egypt by ${ }^{(72)}$ who claimed that caregivers' residence place was unrelated to their knowledge of their patients' diseases and illness.

The finding of the present study illustrated that There is a highly statistically significant relationship between caregiver level of knowledge and their sex. the current study demonstrated that female caregivers had a significantly more unsatisfactory level of knowledge while male caregivers had a significantly more satisfactory level of knowledge this is due to the role of men and women in the caregiving process that man usually overtake the medication and financial sides of caring while women deal with physical sides of caring this was agreement with the findings of ${ }^{(67)}$ who conducted a study in Egypt on the relationship between caregiving burden and knowledge. who revealed that there was a statistically significant relationship between caregiver level of knowledge and gender.

The findings of the present study demonstrated that There is a very highly statistically significant relationship between caregiver level of knowledge and their education is a major indicator of knowledge level; caregivers with a high level of education had a higher level of knowledge than those with a low level of education; this could be due to the essential function of education in enriching caregivers' understanding of their patients' diseases by reading books and finding further details from treating physicians or nurses. This was supported by the study of ${ }^{(69)}$ Who studied Caregivers' Knowledge and Practice in Egypt claimed that there was a highly significant relationship between knowledge and level of education, caregivers with higher school education having a higher mean score of knowledge than those with lower levels of education.

The result of the current study revealed that there is a highly significant relationship between caregivers' level of knowledge and their age that older caregivers had a low level of knowledge satisfactory than younger caregivers. This is consistent with the 
findings of ${ }^{(72)}$ in their study conducted in in Egypt reported that the caregivers' age was related to their level of knowledge.

The finding of the current study found that three variables such as age, gender, and education had a positive correlation with the level of knowledge $(p<.05)$. but the place of residence had a nonsignificant correlation with the level of knowledge.

The findings of the present study illustrated that more than one-quarter and one fifth of the caregivers respectively usually use exercises and Self-distraction to overcome stressors situations and burden of caregiving this was in agreement with the study of ${ }^{(73)}$ in Canda who revealed that more than one - third and less than one - third of caregivers respectively usually used self-Physical activities and restructuring to cope with the burden.

The results revealed that four-fifths of our-fifths of caregivers who used religious coping mechanisms in individuals suffering from anxiety and depression sought relief or were praying to feel better. This was supported by a study conducted in Pakistan by (74) which found that nearly half of their study subjects use religious coping strategies. This contrasted with the findings of the study conducted by ${ }^{(73)}$ in Canada, who discovered that one-fifth of their study sample relied on faith and religion to cope with stress.

The finding of the current study demonstrated more than one-third of the study sample used self-blame and one-fifth used self-distraction techniques to cope with stress and burden, this was supported by the results of the study conducted by ${ }^{(75)}$ in India in their study they mentioned that less than two- fifths of the study sample usually experienced self-blame and less than one - fifth experienced Self-distraction strategies to cope with stress.

The result of the current study revealed that more than - one-tenth of the study sample used acceptance strategy to cope with the stress This contrasted with a study conducted in India by ${ }^{(75)}$ (in which they stated that less than three-quarters of their study sample mainly used acceptance strategy to cope with stress.

The present study results illustrated that less than one- fifth of the caregivers used behavioral disengagement and denial to cope with This is consistent with the findings of (76) in Iran, who found that less than one-quarter of their study sample used avoidance behavioral disengagement and more than one-fifth used resignation as a denial strategy to cope with stress. 


\section{Conclusion}

Based on the findings of the present study, it can be concluded that:

The participants caregivers experienced high level of burden with (43\%), medium level of burden with (32\%) and low level of burden with (25\%) The current study revealed that $(59 \%)$ of studied sample were unsatisfied about their level of knowledge whereas $(41 \%)$. were satisfied.

Caregivers used the main coping strategies problem -focused strategies, emotional - focused strategies, and dysfunctional coping strategies and different techniques to cope with burden and stress associated with it. The burden on caregivers is influenced by a variety of factors. Among these are caregiver variables. include age, gender, educational level, income status, health status, time spent per day, disease awareness, cultural, subjective perception, and coping skills. Patient considerations include Age, clinical symptom, and impairment in everyday life, as well as environmental factors, Health care services and their use, as well as social assistance and supportive ways.

\section{Recommendation}

- Provide guideline as well as clinical training to assist caregivers of chronic disease patients at home This helps them deal with the burden of care and manage the stress associated with it.

- Families should be involved in the care program for older adult patients as this helps to increase their knowledge of the care that older adults need and prevent stress and thus reduce their burden.

- Educate caregivers by developing specific training and educational programs about advanced diseases, its management and caregiving coping strategies which help in reducing care burden and improving patients' outcomes.

- Burden of caregivers could be reduced by improving communication with healthcare providers through social networks, such as What's app, Twitter, telephone calls, and E-mails.

- Intervention studies are proposed to assist caregivers in engaging in behaviors that improve their own wellbeing and in developing successful buffers against feeling depressed and distressed.

Ethical clearance: Taken from ethical research committee, faculty of nursing Beni-Suef University, Egypt. 
Conflict of Interest: No conflict of interest Source of funding: Self-funding

\section{References}

1- Hoca, M.; Türker, P.F. (2017). Kıbrıs Gazimağusa'da Yaşayan Yaşıı Bireylerin Beslenme Alışkanlıkları, Beslenme Durumları ve Yaşam Kalitesinin Değerlendirilmesi. Beslenme ve $\begin{array}{lllll}\text { Diyet } & \text { Dergisi. } & 45 & \text { 44-52. }\end{array}$ https://doi.org/10.33076/2019.bdd.1158

2- Tekin, Ç.S.; Kara, F. (2018). Dünyada ve Türkiye'de Yaşl1lık. Uluslararası Bilimsel Araştırmalar Dergisi (IBAD). 3 (1), 219-229

3- ÜNAL, E., \& ÖZDEMIR, A. (2019). Old Age and Aging. Recent Studies in Health Sciences, 414.

4- World Health Organization. (2018). Ageing and health. Who.int; World Health Organization: WHO. https://www.who.int/news-room/fact-sheets/detail/ageing-and-health

5- United Nations. Department Of Economic and Social Affairs. Population Division. (2020). World population ageing 2020 Highlights: living arrangements of older persons. (ST/ESA/SER.A/451) United Nations.

6- Abdallah, S, Eman\& Mohammed, G, Safia\& Ahmed, M, Fatma. (2017). Effect of Elderly Health Problems on Caregivers' Health at Rural Areas in Sharkia Governorate, Egypt. IOSR Journal of Nursing and Health Science (IOSR-JNHS). 6. 39-49. 10.9790/19590606073949.https://doi.org/10.9790/1959-0601083134

7- El Moselhy, E. A. (2016). Aging: The Current Situation Globally and in Egypt. Journal of Gerontology \& Geriatric Research, 5(5). https://doi.org/10.4172/2167-7182.1000e141

8- Yigitalp, G., Surucu, H. A., Gumus, F., \& Evinc, E. (2017). Predictors of caregiver burden in primary caregivers of chronic patients. International Journal of Caring Sciences, 10(3), 1168

9- Green, H. I. (2020). The Lived Experience of Male Caregivers to Aging Family Members (Doctoral dissertation, Capella University).

10- Roth, D. L., Sheehan, O. C., Haley, W. E., Jenny, N. S., Cushman, M., \& Walston, J. D. (2019). Is Family Caregiving Associated with Inflammation or Compromised Immunity? A MetaAnalysis. The Gerontologist. https://doi.org/10.1093/geront/gnz015

11- Bell, K. E. (2020). Experiences of Resilience among Family Caregivers of Physically or Mentally Ill Family Members (Doctoral dissertation, Capella University).

12- Khalaila, R. (2020). Caregiver Burden and Compassion Fatigue Among Arab Family Caregivers of Older Relatives. Journal of Applied Gerontology, 073346482092010. https://doi.org/10.1177/0733464820920100

13- BEKDEMIR, A., \& İLHAN, N. (2019). Predictors of Caregiver Burden in Caregivers of Bedridden Patients. Journal of Nursing Research, 27(3), e24. https://doi.org/10.1097/jnr.0000000000000297

14- Maguire, R., \& Maguire, P. (2020). Caregiver Burden in Multiple Sclerosis: Recent Trends and Future Directions. Current Neurology and Neuroscience Reports, 20(7). https://doi.org/10.1007/s11910-020-01043-5

15- Sayed, S. H.., Deyab, B. A., \& Hussien, N. K. A., (2020). Predictors of perceived caregiving burden among caregivers of hemodialysis patients. Sylwan. 164. 407-4017.

16- Opara, J., \& Brola, W. (2018). Quality of Life and Burden in caregivers of Multiple Sclerosis patients. Physiotherapy and Health Activity, 25(1), 9-16. https://doi.org/10.1515/pha-2017$\underline{0002}$ 
17- Naing, M. Z., May, S. Y., \& Aung, M. H. (2020). Caregiver burden from caring for dependent elderly in Yangon, The Republic of the Union of Myanmar. Makara Journal of Health Research, 24(1), 3. https://doi.org/10.7454/msk.v24i1.1067

18- Vahidi, M., Mahdavi, N., Asghari, E., Ebrahimi, H., Eivazi Ziaei, J., Hosseinzadeh, M., Namdar Areshtanab, H., \& Kermani, I. A. (2016). Other Side of Breast Cancer: Factors Associated with Caregiver Burden. Asian Nursing Research, 10(3), 201-206. https://doi.org/10.1016/j.anr.2016.06.002

19- Monteiro, A. M. F., Santos, R. L., Kimura, N., Baptista, M. A. T., Dourado, M. C. N., Monteiro, A. M. F., Santos, R. L., Kimura, N., Baptista, M. A. T., \& Dourado, M. C. N. (2018). Coping strategies among caregivers of people with Alzheimer disease: a systematic review. Trends in Psychiatry and Psychotherapy, 40(3), 258-268. https://doi.org/10.1590/2237-6089-2017-0065

20- Kazemi, A., Azimian, J., Mafi, M., Allen, K.-A., \& Motalebi, S. A. (2021). Caregiver burden and coping strategies in caregivers of older patients with stroke. BMC Psychology, 9(1). https://doi.org/10.1186/s40359-021-00556-Z

21- Frey, M. K., Chapman-Davis, E., Glynn, S. M., Lin, J., Ellis, A. E., Tomita, S., Fowlkes, R. K., Thomas, C., Christos, P. J., Cantillo, E., Zeligs, K., Holcomb, K., \& Blank, S. V. (2021). Adapting and avoiding coping strategies for women with ovarian cancer during the COVID19 pandemic. Gynecologic Oncology, 160(2), 492-498. https://doi.org/10.1016/j.ygyno.2020.11.017

22- Miller, C. A. (2019). Nursing for wellness in older adults (8th ed.). Wolters Kluwer.

23- Mauk, K. L. (2018). Gerontological nursing: competencies for care (4th ed.). Jones \& Bartlett Learning

24- Sam, S., Appavu, S., \& Chellappan, S. (2019). Effect of counselling on burden and coping among caregivers of cancer patients with Terminal illness. Asian Journal of Nursing Education and Research, 9(3), 331. https://doi.org/10.5958/2349-2996.2019.00071.5

25- Palacio G, C., Krikorian, A., Gómez-Romero, M. J., \& Limonero, J. T. (2019). Resilience in Caregivers: A Systemati Review. American Journal of Hospice and Palliative Medicine®, 37(8), 648-658. https://doi.org/10.1177/1049909119893977

26- Aylaz, R., \& Yildiz, E. (2017). The care burden and coping levels of chronic psychiatric patients' caregivers. Perspectives in Psychiatric Care, 54(2), 230-241. https://doi.org/10.1111/ppc.12228

27- Sarris, A., Augoustinos, M., Williams, N., \& Ferguson, B. (2020). Caregiving work: The experiences and needs of caregivers in Australia. Health \& Social Care in the Community. https://doi.org/10.1111/hsc.13001

28- Tasmin, S., Sultana, H., Haque, A., Islam, M. M., Alam, M. R., Halim, K. S., \& Abbas, M. G. (2021). Stress and Coping Status among Caregivers of Major Psychiatric Patients. Bangladesh Medical Journal, 49(1), 38-44. https://doi.org/10.3329/bmj.v49i1.52588

29- Marimbe, B. D., Cowan, F., Kajawu, L., Muchirahondo, F., \& Lund, C. (2016). Perceived burden of care and reported coping strategies and needs for family caregivers of people with mental disorders in Zimbabwe. African Journal of Disability, 5(1). https://doi.org/10.4102/ajod.v5i1.209

30- Ahmed, A., Darweesh, A. E. D., Mohamed, I., \& Ahmed, Z. (2020). Correlation Between Socio-Demographic Characteristics and Burden Among Family Caregivers of Psychotic Patients. Education, 47(94), 33-3.

31- Schulz, R., Eden, J., \& National Academies of Sciences, Engineering, and Medicine. (2016). Older adults who need caregiving and the family caregivers who help them. In Families Caring for an Aging America. National Academies Press (US). https:// www. ncbi. nlm. nih. gov/ books/NBK396397/?report=reader 
32- Prudencio, G., \& Young, H. (2020). Caregiving in the U.S. 2020: What Does the Latest Edition of This Survey Tell Us About Their Contributions and Needs? Innovation in Aging, 4(Supplement_1), 681-681. https://doi.org/10.1093/geroni/igaa057.2371

33- Sharma, N., Chakrabarti, S., \& Grover, S. (2016). Gender differences in caregiving among family - caregivers of people with mental illnesses. World Journal of Psychiatry, 6(1), 7. https://doi.org/10.5498/wjp.v6.i1.7

34- Noori, L. K., \& Ebrahim, S. A. (2020). Family Caregivers Burden and Coping strategies for Patient With Schizophrenia in Mosul City. Mosul Journal of Nursing, 8(2), 215-224. (2020). Family Caregivers Burden and Coping strategies for Patient with Schizophrenia in Mosul City. Mosul Journal of Nursing, 8(2), 215-224 https://doi.org/10.33899/mjn.2017.160057

35- Abd El-Ghafar, S. A. E. M., Abd El-Nabi, A. A., \& Fathalla, H. E. D. (2018). Resilience, burden, and quality of life in Egyptian family caregivers of patients with schizophrenia. Egyptian Nursing Journal, 15(2), 196. doi: 10.4103/ENJ.ENJ_1_18

36- Storti, L. B., Quintino, D. T., Silva, N. M., Kusumota, L., \& Marques, S. (2016). Neuropsychiatric symptoms of the elderly with Alzheimer's disease and the family caregivers' distress. Revista latino-americana de enfermagem, 24.

37- Sabzwari, S., Badini, A., Fatmi, Z., \& Shah, S. (2016). Burden and associated factors for caregivers of the elderly in a developing country. Eastern Mediterranean Health Journal, 22(6), 394-403. https://doi.org/10.26719/2016.22.6.394

38- Alshammari, S., Alzahrani, A., Alabduljabbar, K., Aldaghri, A., Alhusainy, Y., Khan, M., Alshuwaier, R., \& Kariz, I. (2017). The burden perceived by informal caregivers of the elderly in Saudi Arabia. Journal of Family and Community Medicine, 24(3), 145. https://doi.org/10.4103/jfcm.jfcm_117_16

39- Bishop, M., \& Greeff, A. P. (2015). Resilience in families in which a member has been diagnosed with schizophrenia. Journal of Psychiatric and Mental Health Nursing, 22(7), 463471. https://doi.org/10.1111/jpm.12230

40- Geriani, D. (2015). Burden of Care on Caregivers of Schizophrenia Patients: A Correlation to Personality and Coping. JOURNAL of CLINICAL and DIAGNOSTIC RESEARCH. https://doi.org/10.7860/jcdr/2015/11342.5654

41- Alsirafy, S. A., Abdel-Kareem, S. S., Ibrahim, N. Y., Abolkasem, M. A., \& Farag, D. E. (2016). Cancer diagnosis disclosure preferences of family caregivers of cancer patients in Egypt. Psycho-Oncology, 26(11), 1758-1762. https://doi.org/10.1002/pon.4206

42- Alnazly, E. K. (2016). Burden and coping strategies among Jordanian caregivers of patients undergoing hemodialysis. Hemodialysis International, 20(1), 84-93. https://doi.org/10.1111/hdi.12318

43- Okafor, C. J., \& Emedoh, T. (2021). Caregivers of schizophrenic patients in Calabar: Extent and predictors of burden. Calabar Journal of Health Sciences, 4, 48-56. https://doi.org/10.25259/cjhs 242020

44- Abu Kamel, A. A., Bond, A. E., \& Froelicher, E. S. (2012). Depression and caregiver burden experienced by caregivers of Jordanian patients with stroke. International Journal of Nursing Practice, 18(2), 147-154. https://doi.org/10.1111/j.1440-172x.2012.02011.x

45- Abu Kamel, A. M. (2015). Who are the elder's caregivers in Jordan: A cross-sectional study. Journal of Nursing Education and Practice, 6(3). https://doi.org/10.5430/jnep.v6n3p116

46- Mohmed, A. A. E., Darweesh, A. E. D. M., Mohamed, I. I., \& Ahmed, Z. A. (2019). Assessment of Coping Strategies Among Family Caregivers of Psychotic Patients. Assiut Scientific Nursing Journal, 7(16), 131-138.

47- El-Sherbiny, N. A., Younis, A., \& Masoud, M. (2016). A comprehensive assessment of the physical, nutritional, and psychological health status of the elderly populace in the Fayoum 
Governorate (Egypt). Archives of Gerontology and Geriatrics, 66, 119-126. https://doi.org/10.1016/j.archger.2016.06.001

48- AbdAllah, S, Eman\& Mohammed, G, Safia\& Ahmed, M, Fatma. (2017). Effect of Elderly Health Problems on Caregivers' Health at Rural Areas in Sharkia Governorate, Egypt. IOSR Journal of Nursing and Health Science (IOSR-JNHS). 6. 39-49. 10.9790/19590606073949.https://doi.org/10.9790/1959-0601083134

49- Long, N. X., Pinyopasakul, W., Pongthavornkamol, K., \& Panitrat, R. (2019). Factors predicting the health status of caregivers of stroke survivors: A cross-sectional study. Nursing \& Health Sciences, 21(2), 262-268. https://doi.org/10.1111/nhs.12591

50- Manzini, C. S. S., Brigola, A. G., Pavarini, S. C. I., \& Vale, F. A. C. (2016). Factors associated with the resilience of family caregivers of persons with dementia: a systematic review. Revista Brasileira de Geriatria E Gerontologia, 19(4), 703-714. https://doi.org/10.1590/180998232016019.150117

51- Caro, C. C., Costa, J. D., \& Da Cruz, D. M. C. (2018). Burden and Quality of Life of Family Caregivers of Stroke Patients. Occupational Therapy in Health Care,32(2), 154-171. https://doi.org/10.1080/07380577.2018.1449046

52- Abdel Aal, M. H. (2017). Relation between Expressed Emotion and Burden among Family Caregivers of Patients with Dementia. Port Said Scientific Journal of Nursing, 4(1), 40-61.

53- Parekh, N. K., Shah, S., McMaster, K., Speziale, A., Yun, L., Nguyen, D. L., ... \& Kane, S. (2017). Effects of caregiver burden on quality of life and coping strategies utilized by caregivers of adult patients with inflammatory bowel disease. Annals of Gastroenterology: Quarterly Publication of the Hellenic Society of Gastroenterology,30(1), 89. https://doi.org/10.20524/aog.2016.0084

54- Faronbi, J. O. (2018). Correlate of burden and coping ability of caregivers of older adults with chronic illness in Nigeria. Scandinavian Journal of Caring Sciences, 32(4), 1288-1296. https://doi.org/10.1111/scs.12572

55- Abdel Hady Ghaith, R., \& Mahmoud Mohammed, S. (2018). Relationship between burden, psychological well-being, and social support among caregivers of mentally ill patients. Egyptian Nursing Journal, 15(3), 268. https://doi.org/10.4103/enj.enj_17 18

56- Oyegbile, Y. O., \& Brysiewicz, P. (2017). Exploring caregiver burden experienced by family caregivers of patients with End-Stage Renal Disease in Nigeria. International Journal of Africa Nursing Sciences, 7, 136-143. https://doi.org/10.1016/j.ijans.2017.11.005

57- El-Bilsha, M. A. (2019). Effect of Family Intervention on Family Caregivers' Burden, Depression, Anxiety and Stress among Relatives of Depressed Patients. Middle East Journal of Age and Ageing, 16(1), 3-13. https://doi.org/10.5742/mejaa.2019.93619

58- Elkharadly, E. G. (2020). Factors Associated with Family Caregivers' Burden of Geriatric Patients with Cancer Receiving Chemotherapy (Master's thesis, Alexandria University. Egypt, 2020). Alexandria: Alexandria University.

59- Elkafrawy, L., Mounir, E., Emad Eldin, M., \& Abd Elhameed, S. (2019). CAREGIVING BURDEN AND COPING STRATEGIES OF CAREGIVERS CARING FOR ELDERLY WITH END STAGE RENAL DISEASE. Mansoura Nursing Journal, 6(2), 95-106. https://doi.org/10.21608/mnj.2019.154760

60- Hamdi, Samiha \& Deyab, Basma \& Kamel, Naglaa. (2020). Predictors of perceived caregiving burden among caregivers of hemodialysis patients. Sylwan. 164. 407-4017.

61- Mohammed, Asmaa Ali, et.al. (2020) "Relationship between Caregiving Burden and Health Status of Elderly Patients with Parkinson's Disease". IOSR Journal of Nursing and Health Science (IOSRJNHS), 9(1), 2020, pp. 47-5 https://DOI: 10.9790/1959-0901024759

62- Brigola, A. G., Luchesi, B. M., Alexandre, T. da S., Inouye, K., Mioshi, E., \& Pavarini, S. C. I. (2017). High burden and frailty: association with poor cognitive performance in older 
caregivers living in rural areas. Trends in Psychiatry and Psychotherapy, 39(4), 257-263. https://doi.org/10.1590/2237-6089-2016-0085

63- Modi, N., Mehta, R., Chaudhary, P., \& Dave, K. (2020). A study of disability profile and burden in caregivers of stable schizophrenia patients. Neuropsychiatric I Neuropsychologia, 15(3-4), 108-115. https://doi.org/10.5114/nan.2020.101293

64- Abd Elhameed, S., \& Alam, R. (2016). Burden of caring for chronic diseases and family caregivers health status. Alexandria Scientific Nursing Journal, 18(1), 43-60.

65- Unver, V., Basak, T., Tosun, N., Aslan, O., \& Akbayrak, N. (2016). Care Burden and SelfEfficacy Levels of Family Caregivers of Elderly People in Turkey. Holistic Nursing Practice, 30(3), 166-173. https://doi.org/10.1097/hnp.0000000000000148

66- Sousa, M. F. B., Santos, R. L., Turró-Garriga, O., Dias, R., Dourado, M. C. N., \& Conde-Sala, J. L. (2016). Factors associated with caregiver burden: comparative study between Brazilian and Spanish caregivers of patients with Alzheimer's disease (AD). International Psychogeriatrics, 28(8), 1363-1374. https://doi.org/10.1017/s1041610216000508

67- Refaat Alam, R., Hassan Mounir Radwan, E., \& Mohamed Hassan Saleh, N. (2021). Relationship between Caregiving Burden, knowledge, and stigma of Caregivers Caring for Older Adults with Alzheimer disease. Egyptian Journal of Health Care, 12(2), 332-344. https://doi.org/10.21608/ejhc.2021.153171

68- Xiao, P., \& Zhou, Y. (2020). Factors associated with the burden of family caregivers of elderly patients with femoral neck fracture: a cross-sectional study. Journal of Orthopaedic Surgery and Research, 15(1). https://doi.org/10.1186/s13018-020-01749-9

69- Mersal, F. (2014). Caregivers' Knowledge and Practice Regarding Prevention of Immobilization Complications in El-demerdash Hospital Cairo Egypt. Am J Res Commun, 2, 78-98.

70- Ciancio, N., Sanguinetti, C. M., Falcone, F., Taranto, C., Fasani, R., De Benedetto, F., Resta, O., De Michele, F., Messina, R., Rossi, A., Nardini, S., \& Di Maria, G. (2016). Most Italians attending a congress on health of elderly people do not know and do not recognize respiratory diseases. Multidisciplinary Respiratory Medicine, 11(1). https://doi.org/10.1186/s40248-016$\underline{0062-3}$

71- Abullais, S. S., Al-Shahrani, F. M. F., Al-Gafel, K. M. S., Saeed, A.-H. A., Al-Mathami, S. A., Bhavikatti, S. K., \& Khan, A. A. G. (2020). The Knowledge, Attitude and Practices of the Caregivers about Oral Health Care, at Centers for Intellectually Disabled, in Southern Region of Saudi Arabia. Healthcare, 8(4), 416. https://doi.org/10.3390/healthcare8040416

72- Gabra, R. H., Ebrahim, O. S., Osman, D. M. M., \& Al-Attar, G. S. T. (2020). Knowledge, attitude and health-seeking behavior among family caregivers of mentally ill patients at Assiut University Hospitals: a cross-sectional study. Middle East Current Psychiatry, 27(1). https://doi.org/10.1186/s43045-020-0015-6

73- Branger, C., Burton, R., O’Connell, M. E., Stewart, N., \& Morgan, D. (2014). Coping with cognitive impairment and dementia: Rural caregivers' perspectives. Dementia, 15(4), 814831. https://doi.org/10.1177/1471301214539956

74- Kasi, P. M., Naqvi, H. A., Afghan, A. K., Khawar, T., Khan, F. H., Khan, U. Z., Khuwaja, U. B., Kiani, J., \& Khan, H. M. (2012). Coping Styles in Patients with Anxiety and Depression. ISRN Psychiatry, 2012, 1-7. https://doi.org/10.5402/2012/128672

75- Kumar, R., Kaur, S., \& K, R. (2015). Burden and Coping Strategies in Caregivers of Stroke Survivors. Journal of Neurology and Neuroscience, 06(s1). https://doi.org/10.21767/2171$\underline{6625 . s 10005}$

76- Rahmani, F., Ranjbar, F., Hosseinzadeh, M., Razavi, S. S., Dickens, G. L., \& Vahidi, M. (2019). Coping strategies of family caregivers of patients with schizophrenia in Iran: A crosssectional survey. International Journal of Nursing Sciences, 6(2), 148-153. https://doi.org/10.1016/j.ijnss.2019.03.006 